Original Article

\title{
The relationship between physical fitness and academic achievement among adolescent in South Korea
}

\author{
Gun-Soo Han, PhD ${ }^{1)}$ \\ 1) Department of Sports and Leisure Studies, College of Humanity, Daegu University: Jillyang, \\ Gyeongsan, Gyeongbuk 38453, Republic of Korea
}

\begin{abstract}
Purpose] The purpose of this study was to identify the relationship between physical fitness level and academic achievement in middle school students. [Subjects and Methods] A total of 236 students aged 13-15 from three middle schools in D city, South Korea, were selected using a random sampling method. Academic achievement was measured by students' 2014 fall-semester final exam scores and the level of physical fitness was determined according to the PAPS (Physical Activity Promotion System) score administrated by the Korean Ministry of Education. A Pearson correlation test with SPSS 20.0 was employed. [Results] The Pearson correlation test revealed a significant correlation between physical fitness and academic achievement. Specifically, students with higher levels of physical fitness tend to have higher academic performance. In addition, final exam scores of core subjects (e.g., English, mathematics, and science) were significantly related to the PAPS score. [Conclusion] Results of this study can be used to develop more effective physical education curricula. In addition, the data can also be applied to recreation and sport programs for other populations (e.g., children and adult) as well as existing national physical fitness data in various countries.

Key words: Physical fitness, Academic achievement, Adolescent
\end{abstract}

(This article was submitted Dec. 19, 2017, and was accepted Jan. 23, 2018)

\section{INTRODUCTION}

Physical activity is an interesting research subject affecting both physical and psychological wellbeing, including forming a positive body image, relieving depression, and increasing life satisfaction ${ }^{1-3)}$. In addition, there is evidence that physical activity promotes intelligence and brain development. Intelligence can be defined as "the aggregate or global capacity of the individual to act purposefully, to think rationally, and to deal effectively with his environment"4). Intelligence has been examined in numerous studies and in a wide range of research areas. One of earliest studies on intelligence was conducted by Alfred Binet. He is considered the first researcher who tried to measure and score intelligence with the standardized scale, known as the Binet-Simon Scale ${ }^{5}$. Following Alfred Binet, William Stern established and introduced an intelligence scale, the Intelligence Quotient (IQ) ${ }^{6}$.

In the sport research field, previous studies have examined the positive effects of physical activity on intelligence and brain development using various intelligence measurements such as MRI (Magnetic Resonance Imaging), memory test, concentration test, and cognition test ${ }^{7-10}$. For example, Corder ${ }^{11)}$ found that complex fitness training during a 20-day program increased children's intelligence test scores (i.e., Wechsler Intelligence Scale for Children) by analyzing 24 children aged 12-16 years old. Zervas, Danis, and Klissouras ${ }^{8)}$ concluded that aerobic exercise significantly increased cognition among 26 children aged 11-14 years old. Ji-ying's study ${ }^{12}$ indicated that the Intelligence Quotient (IQ) score increased following a six-month gymnastics training program among 186 children aged 4-7 years old. Colcombe, Erickson, Scalf, et al. ${ }^{7)}$ also

Corresponding author. Gun-Soo Han (E-mail: gunsoo@gmail.com)

(C2018 The Society of Physical Therapy Science. Published by IPEC Inc.

(c) (1) $\odot$ This is an open-access article distributed under the terms of the Creative Commons Attribution Non-Commercial No Deriva-

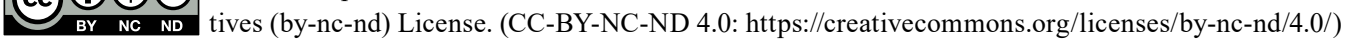


Table 1. Mean and Standard Deviation for measured values

\begin{tabular}{|c|c|c|c|c|c|c|c|c|c|}
\hline $\begin{array}{l}\text { Vari- } \\
\text { ables }\end{array}$ & Korean & Sociology & History & Math & Science & $\begin{array}{c}\text { Home } \\
\text { economics }\end{array}$ & English & Chinese & PAPS \\
\hline
\end{tabular}

Scores $79.38 \pm 13.2074 .52 \pm 15.4979 .51 \pm 18.9473 .04 \pm 17.1372 .26 \pm 22.9372 .69 \pm 14.6170 .81 \pm 20.9769 .98 \pm 21.62 \quad 2.00 \pm 0.76$

Values are mean $\pm \mathrm{SD}$

found that a six-month aerobic fitness training program increased the volume of gray and white matter regions of the brain by analyzing 69 people aged 60-79 years old. Budde, Voelcker-Rehage, Pietrabyk-Kendziorra, et al.9) found that complex physical training programs increased concentration by stimulating brain function among 99 children aged 13-16 years old.

Academic achievement might be a direct indicator of intelligence in school education. However, limited research has focused on the effects of physical activity on academic performance. South Korea, as well as many other countries, focuses on increasing students' academic achievement by investing in excess of 1,600 billion dollars in private education ${ }^{13)}$. In other words, identifying the relationship between physical activity and academic achievement would be applied to establish more practical education policies and teaching methods. In addition, the importance of physical education in schools might be increased. Therefore, this study examines the relationship between physical activity and academic achievement among middle school students in South Korea.

\section{SUBJECTS AND METHODS}

A total of 236 students from three middle schools in D city, South Korea, were selected using a random sampling method. Before starting this study, all subjects completed an informed consent. First, three middle schools in D city were randomly selected. Second, 100 students from each middle school were randomly selected, making a total of 300 students. Of the 300 students selected, 64 were removed due to difficulties in obtaining data concerning physical fitness and final exam score. This study examines the two main factors of academic achievement and physical fitness. Academic achievement was measured by students' 2014 fall-semester final exam scores and the level of physical fitness was determined by PAPS (Physical Activity Promotion System) scores (Table 1).

Final exam subjects consist of Korean language, sociology, history, mathematics, science, home economics, English, and Chinese characters. Each subject's raw score was used for analysis rather than grades (e.g., A, B, C). PAPS is evaluated by the Korean Ministry of Education by measuring students' physical fitness level (e.g., cardiovascular endurance, flexibility, muscle strength / endurance, power, and BMI) from elementary school to high school. Cardiovascular endurance was measured by a shuttle run; flexibility was assessed by a sitting trunk flexion; muscle strength was assessed by push-ups; and power was measured by a 50-meter sprint. Each component of physical fitness is categorized into 5 grades, including 1 "very high", 2 "high", 3 "average", 4 "low", and 5 "very low". Therefore, a lower grade indicates a higher level of physical fitness for students. Approval for this study was obtained from the Institutional Review Board of Daegu University. All personal information (e.g., name and class number) was removed and replaced by a randomly assigned ID number. Data was collected from March 9-March 16, 2015, with the approval of each school. The Statistical Package for the Social Sciences (SPSS 20.0) was used for analysis. The Pearson correlation test was employed to identify the relationship between physical fitness level and academic achievement, with acceptable significance values of $\mathrm{p}<0.05$.

\section{RESULTS}

The most common physical fitness level among participants was high (PAPS grade 2; 49.6\%) followed by very high (PAPS grade $1 ; 26.3 \%$ ), average (PAPS grade $3 ; 21.6 \%$ ), and low (PAPS grade $4 ; 2.5 \%$ ). No student was evaluated as very low (PAPS grade 5). In terms of BMI (Body Mass Index), most students were categorized as normal weight (77.1\%). However, 14.4 percent of students were considered as obese or morbidly obese.

The Pearson correlation test indicated a significant negative relationship between PAPS grade (a lower grade of PAPS indicates a higher level of physical fitness) and final exam score (Table 2). Therefore, students with higher levels of physical fitness tend to have higher academic achievement. Furthermore, the final exams for all subjects were significantly related to the PAPS grade (physical fitness level).

\section{DISCUSSION}

The purpose of this study was to examine the relationship between physical activity and academic performance. Specifically, physical fitness level was measured according to the PAPS (Physical Activity Promotion System), and raw scores of final exams for high school students in South Korea were used for analysis. Results indicated a significant relationship between physical fitness level and final exam scores. This finding supports previous studies regarding the effects of physical activity on academic achievement in several different countries $\left.{ }^{14}, 15\right)$. Two studies involving a large sample size were examined in 
Table 2. Correlation between PAPS (Physical Activity Promotion System) and academic performance

\begin{tabular}{llllllllll}
\hline Variables & 1 & 2 & 3 & 4 & 5 & 6 & 7 & 8 & 9 \\
\hline 1. Korean & 1 & & & & & & & & \\
2. Sociology & $0.80^{* *}$ & 1 & & & & & & \\
3. History & $0.78^{* *}$ & $0.84^{* *}$ & 1 & & & & & & \\
4. Math & $0.78^{* *}$ & $0.72^{* *}$ & $0.67^{* *}$ & 1 & & & & & \\
5. Science & $0.79^{* *}$ & $0.79^{* *}$ & $0.74^{* *}$ & $0.79^{* *}$ & 1 & & & & \\
6. Home economics & $0.74^{* *}$ & $0.82^{* *}$ & $0.77^{* *}$ & $0.70^{* *}$ & $0.75^{* *}$ & 1 & & & \\
7. English & $0.77^{* *}$ & $0.72^{* *}$ & $0.68^{* *}$ & $0.80^{* *}$ & $0.80^{* *}$ & $0.69^{* *}$ & 1 & & \\
8. Chinese & $0.72^{* *}$ & $0.79^{* *}$ & $0.79^{* *}$ & $0.72^{* *}$ & $0.74^{* *}$ & $0.81^{* *}$ & $0.71^{* *}$ & 1 \\
9. PAPS & $-0.15^{*}$ & $-0.16^{*}$ & $-0.20^{* *}$ & $-0.15^{*}$ & $-0.14^{*}$ & $-0.20^{* *}$ & $-0.21^{* *}$ & $-0.17^{* *}$ & 1 \\
\hline
\end{tabular}

$* * 0.01, * 0.05$.

Australia and the U.S. Dwyer, Sallis, Blizzard, Lazarus and Dean ${ }^{14)}$ analyzed approximately 9,000 Australian students aged from 7-15 years from 109 schools. They measured physical fitness level (e.g., cardiovascular endurance, muscle strength, power) and academic achievement directly obtained from schools. They found a significant positive correlation between physical fitness level and academic achievement. The California Department of Education examined approximately one million students ${ }^{15)}$. They used national data concerning physical fitness level including aerobic capacity, body composition, strength, and flexibility. In addition, the California standards test assessing language, arts, and mathematics proficiency was used to identify academic achievement. Results indicated a positive correlation between physical fitness level and academic achievement. Specifically, physical fitness level of students in the 5th, 7th, and 9th grades were more strongly correlated with academic achievement, and girls showed a stronger correlation than boys. Castelli, Hillman, Buck et al.'s study ${ }^{16)}$ used a relatively small sample size of 259 students. They measured physical fitness level such as aerobic performance, flexibility, and muscular strength, and found that aerobic performance had a positive effect on reading achievement, mathematics, and total academic achievement.

Subsequent studies are required based on the limitations of this study in order to further identify the effect of physical activity on intelligence and brain development. First, this study used only five components of physical fitness, which included cardiovascular endurance, flexibility, muscle strength/endurance, power, and BMI. Thus, future studies need to include more diverse components of physical fitness by dividing it into two categories such as health-related physical fitness and skillrelated physical fitness ${ }^{17}$. Second, this study used comprehensive physical fitness level for analysis, rather than using each component of physical fitness separately. Therefore, future studies should analyze the effects of each component of physical fitness on academic achievement.

In summary, this study specifically identified the relationship between physical fitness level and academic achievement. Results of this study can be used to develop more effective physical education curricula since raw exam scores were directly used for analysis. Moreover, results of this study can also be applied to recreation and sport programs regarding other populations (e.g., children and adult) as well as using existing national physical fitness data, such as "national fitness award" measured by the Korea Sports Promotion Foundation.

\section{Funding}

This research was supported by the Daegu University Research Grant, 2015.

\section{Conflict of interest}

None.

\section{REFERENCES}

1) Bartholomew JB, Morrison D, Ciccolo JT: Effects of acute exercise on mood and well-being in patients with major depressive disorder. Med Sci Sports Exerc, 2005, 37: 2032-2037. [Medline] [CrossRef]

2) Ekkekakis P: Pleasure and displeasure from the body: perspectives from exercise. Cogn Emotion, 2003, 17: 213-239. [CrossRef]

3) Rudolph DL, McAuley E: Self-efficacy and salivary cortisol responses to acute exercise in physically active and less active adults. J Sport Exerc Psychol, 1995, 17: 206-213. [CrossRef]

4) Wechsler D: The measurement of adult intelligence. Baltimore: Williams and Wilkins, 1939, p. 3.

5) Binet A, Simon T: L'intelligence des imbeciles. Annee Psychol, 1908, 15: 1-147. [CrossRef]

6) Stern W: Psychologischen Methoden der Intelligenz-Prüfung. Leipzig: Barth, 1912.

7) Colcombe SJ, Erickson KI, Scalf PE, et al.: Aerobic exercise training increases brain volume in aging humans. J Gerontol A Biol Sci Med Sci, 2006, 61: 
1166-1170. [Medline] [CrossRef]

8) Zervas Y, Danis A, Klissouras V: Influence of physical exertion on mental performance with reference to training. Percept Mot Skills, 1991, 72: 1215-1221. [Medline] [CrossRef]

9) Budde H, Voelcker-Rehage C, Pietrabyk-Kendziorra S, et al.: Acute coordinative exercise improves attentional performance in adolescents. Neurosci Lett, 2008, 441: 219-223. [Medline] [CrossRef]

10) Kwok TC, Lam KC, Wong PS, et al.: Effectiveness of coordination exercise in improving cognitive function in older adults: a prospective study. Clin Interv Aging, 2011, 6: 261-267. [Medline]

11) Corder WO: Effects of physical education on the intellectual, physical, and social development of educable mentally retarded boys. Except Child, 1966, 32: 357-364. [Medline] [CrossRef]

12) Ji-ying Y: Effects of basic gymnastics exercise on children's intelligence development. Sport Sci (Travnik), 2000, 20: 75-79.

13) Statistics Korea: 2013 private education expanses survey. Seoul: Statistics Korea, 2014.

14) Dwyer T, Sallis JF, Blizzard L, et al.: Relation of academic performance to physical activity and fitness in children. Pediatr Exerc Sci, 2001, 13: 225-237. [CrossRef]

15) California Department of Education: A study of the relationship between physical fitness and academic achievement in California using 2004 test results. Sacramento: California Department of Education, 2005.

16) Castelli DM, Hillman CH, Buck SM, et al.: Physical fitness and academic achievement in third- and fifth-grade students. J Sport Exerc Psychol, 2007, 29: 239-252. [Medline] [CrossRef]

17) Pate RR: A new definition of youth fitness. Physician Sport Med, 1983, 11: 77-83. [CrossRef] 